\title{
Diacronie
}

Studi di Storia Contemporanea

$\mathrm{N}^{\circ} 20,4 \mid 2014$

II diritto militante

\section{Mussolini, Franco y los judíos: una relación controvertida}

David Pérez Guillén

\section{Q OpenEdition \\ Journals}

Edición electrónica

URL: https://journals.openedition.org/diacronie/1754

DOI: $10.4000 /$ diacronie. 1754

ISSN: 2038-0925

Editor

Association culturelle Diacronie

Referencia electrónica

David Pérez Guillén, «Mussolini, Franco y los judíos: una relación controvertida», Diacronie [En línea], № 20, 4 | 2014, documento 12, Publicado el 01 diciembre 2014, consultado el 21 septiembre 2021. URL: http://journals.openedition.org/diacronie/1754 ; DOI: https://doi.org/10.4000/diacronie.1754 


\section{Diacronie}

\section{2/}

\section{Mussolini, Franco y los judíos: una relación controvertida}

David PÉREZ GUILLÉN *

Son muchas las investigaciones realizadas sobre la situación de los judíos en la Alemania de Hitler, sin embargo, hay una clara deficiencia de estudios científicos sobre las comunidades judías bajo las dictaduras de Mussolini y Franco, especialmente en el último caso. Este artículo contribuye al conocimiento de la controvertida relación que estas dictaduras del Sur de Europa mantuvieron con sus respectivas comunidades judías, y profundiza, en perspectiva comparada y desde el ámbito historiográfico, en los puntos de convergencia y divergencia entre ambos poderes dictatoriales y su relación con lo judío, analizándose las similitudes en cuanto a las acciones llevadas a cabo contra los judíos.

\section{Introdución}

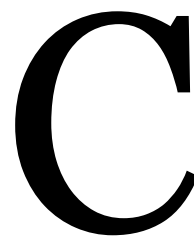

on este artículo pretendemos contribuir a la producción historiográfica de lo que Jaime Contreras definió, en uno de sus artículos, como «historiar a los judíos»1, y puesto que nos encontramos ante un artículo científico, con espacio limitado, no es posible, ni lo pretendemos, hacer una "historia total" de los judíos, como puede ser la obra de Paul Johnson, convertida ya en referencia mundial2. Lo que

${ }^{1}$ CONTRERAS CONTERAS, Jaime, Historiar a los judios: un asunto de pueblo, nación y etnia, in Actas de la IV Reunión Científica de la Asociación Española de Historia Moderna de Alicante, vol.2, 1997, pp. 117-144.

2 Véase JOHNSON, Paul, La historia de los judíos, Barcelona, Ediciones B, 2006. 
pretendemos, en palabras de Elder y Paul, hablando de la lógica de la Historia, es «crear una "historia" sobre el pasado que capture su dinámica»3, en este caso sobre el pasado de las comunidades judías españolas e italianas en la primera mitad del siglo XX.

Esta investigación, que se inscribe en el ámbito de la Historia Social Comparada, va más allá del estudio aislado de las comunidades judías en Italia y España bajo los regímenes dictatoriales de Mussolini y Franco, para comprobar si el trato aplicado a las comunidades judías afincadas en sus respectivos territorios fue similar o divergente. El análisis de la documentación recabada para este artículo permitirá comprobar esta realidad histórica4.

No son muchos los autores que han dedicado sus obras al estudio de los judíos en la Historia de la España Contemporánea, y de todos es conocido que el tema judaico ha interesado mucho más a medievalistas, y en los últimos años a arqueólogos, que a los historiadores cuya investigación se centra en los siglos XIX y, sobre todo, XX. No es de extrañar este hecho, pues ni siquiera la pregunta ¿qué son los judíos? es baladí, a pesar de su aparente inocencia. Como consecuencia directa de esto, la escasez de obras se hace especialmente evidente en el caso español, no tanto así en el italiano. Aun con ello, no podemos minusvalorar las obras que ya han sido publicadas, pues de no ser así, este tipo de investigaciones no se podrían llevar a cabo. Como decía Bernardo de Chartres, «somos enanos a hombros de gigantes», y si podemos ver más lejos, ir más allá, es gracias a la dedicación y el trabajo de los historiadores que nos han precedido: H. Avni, R. Rein, Lustiger o B. Rother, entre otros.

\footnotetext{
3 ELDER, Linda, PAUL, Richard, Los fundamentos del pensamiento analítico, p. 33, en URL: http://www.criticalthinking.org/resources/PDF/SP-Pensamientoanal\%C3\%ADtico.pdf [visitado el 15 de julio 2014].

4 Quisiera agradecer a los evaluadores externos (colaboradores de la revista Diacronie. Studi di Storia Contemporanea) su valoración del artículo y sus propuestas de mejora que, sin duda, han contribuido a enriquecer este trabajo.
} 


\section{El caso italiano: un aliado del Tercer Reich}

\subsection{El pueblo judío italiano en el periodo prefascista}

El periodo que se extiende desde 1900 a 1920 en Italia nos presenta a los judíos totalmente insertados en la sociedad italiana, sin ningún tipo de recelo; además, su presencia es importante, tanto cuantitativa como cualitativamente, haciéndose esto último especialmente evidente en la ocupación por judíos italianos de puestos políticos de especial delicadeza y de marcado carácter nacional, como pudieron ser la Presidencia del Consejo de Ministros (Luigi Luzzati), el Ministerio de Guerra (Giuseppe Ottolenghi) o el curioso caso del Ministerio de Gracia y Justicia y de los Cultos - de todos los cultos existentes(Ludovico Mortara). No puede pasar desapercibido el hecho de encontrar a un judío como máximo encargado de los cultos, también del cristiano.

En palabras de Eugenio Artom, el judío «vive su vida de trabajo y su mentalidad basándose únicamente en la nación y no como miembro del colectivo hebraico, escogiendo la política, el arte, la filosofía, los partidos y las escuelas, aquéllos que mejor se correspondían con sus propias tendencias personales», mientras otros, además, «reniegan pertenecer a la religión de sus padres y abandonan la comunidad, proclamando el laicismo de su pensamiento y de su vida»5. Vemos que lejos de ser un grupo aislado y extraño, el judío era un italiano más, y su participación y compromiso con la sociedad italiana fue tan estrecha, que incluso lo encontramos en los partidos políticos, siendo curiosa su militancia en el Partido nacional fascista (Pnf) en los primero años pero, eso sí, sin llegar a ocupar puestos relevantes ni a formar parte de grupos dirigentes. Tal es su reconocimiento dentro de la sociedad, que Italia se pronunció oficialmente a favor de un «Centro nacional judío»6, hecho que constituyó para los judíos

\footnotetext{
5 SARFATTI, Michele, Gli ebrei nell'Italia fascista. Vicende, identità, persecuzione, Torino, Einaudi, 2007, p. 13.

6 En este largo proceso de reconocimiento influyó también, desde el impacto del libro de Theodor Herlz, El Estado de los judíos (1896), hasta la Declaración Balfour formulada en noviembre de 1917 por el ministro de Asuntos Exteriores británico, Arthur James Balfour, en la que comunicaba a la comunidad sionista en Londres, mediante carta, que 'el gobierno de Su Majestad contemplaba favorablemente el establecimiento de una patria nacional para el pueblo
} 
italianos un estímulo moderno y concreto en la redefinición de la propia pertenencia judía, italiana y judeo-italiana.

En cuanto al bando ideológico y político opuesto al Pnf, se puede observar la participación de judíos en el periódico antifascista Critica Sociale a través de los índices anuales de autores, al igual que está constatada la adhesión de un significativo número de ellos al manifiesto antifascista de Benedetto Croce (1 mayo 1925). En cambio, nada se sabe de la dimensión cuantitativa de la adhesión de los judíos a movimientos políticos de orientación marxista o liberal en estos años. A pesar de todo, y en opinión de Piero Treves, «los judíos antifascistas eran, respecto a los judíos fascistas o filofascistas, una proporción muy superior a la media nacional»7.

\subsection{Las leyes raciales (1938): la persecución de los derechos}

Los judíos italianos gozaban de una total emancipación jurídica desde el siglo XIX, en estrecha relación con el proceso del Risorgimento y la unidad nacional. Ya en 1930-1931 se sancionó la existencia de veinticinco comunidades judías, pertenecientes a la Ucii (Unione delle comunità israelitiche italiane), dirigida por un Consejo, una Junta y un Presidente. Esto no significaba estar al margen de la sociedad, siendo Ravenna quien reafirmaba la "italianidad" de todo el grupo dirigente de la Ucii:

\footnotetext{
L'Unione cree que es un deber para los judíos libres como somos nosotros, participar, con el consenso del gobierno, en las reuniones y las conferencias [...], adoptando medidas de orden económico, social y político, capaces de aliviar la miseria de los miles de perseguidos y resolver su grave problema moral y material ${ }^{\text {. }}$.
}

De hecho, antes de dar comienzo la persecución de los judíos en Italia, las fuentes indican que el número de matrimonios mixtos se situaba cerca de igualar al de matrimonios propiamente judíos, lo que supondrá un especial

judío en Palestina'. Véase SEGURA, Antoni, Más allá del islam. Política y conflictos actuales en el mundo contemporáneo, Madrid, Alianza Editorial, 2001, p. 238.

7 SARFATTI, Michele, Gli ebre nell'Italia fascista, cit., p. 25.

8 Ibidem, p. 114. 
problema para los legisladores racistas y la burocracia nacional a la hora de querer llevar a cabo una clasificación con fines persecutorios.

No será hasta 1938 cuando Mussolini declare oficialmente antisemita al Pnf. No obstante, con anterioridad, en su etapa en el Partido socialista italiano, el Duce ya había hecho declaraciones de marcado carácter antisemita: presentación de los judíos como el pueblo deicida, ataques a banqueros judíos de Londres y Nueva York, defensa de la civilización heleno-latina, etc. Mussolini llegó incluso a afirmar en uno de sus discursos que esperaba que los judíos italianos continuaran siendo lo suficientemente inteligentes para no suscitar el antisemitismo que hasta entonces no había existido en la península.

No obstante, durante los primeros años de su gobierno, Mussolini desarrolló una posición ambigua y confusa con respecto al tema judío9: condenó la adhesión de judíos italianos al sionismo pero no el sionismo como movimiento nacional, e instó a los judíos a nacionalizarse e integrarse en el fascismo nacional, mientras defendía la catolicidad del país.

Entre las primeras medidas persecutorias de Mussolini estará un lento y progresivo alejamiento de los judíos de esos altos cargos del Estado y posiciones privilegiadas que hemos visto que ostentaban, sustituyéndolos de manera escalonada. Esa política ambigua y lenta a la que hacemos referencia, se convertirá en los años 30 en una política antijudía pública, generalizada y explícita $^{10}$. A pesar de la inexistencia de antisemitismo a la que el propio Mussolini hacía referencia en uno de sus discursos, el Duce tendrá que superar precisamente dicha carencia y convertir a Italia, en tan sólo siete años, en un país oficialmente antisemita, tal y como afirma Bartosová ${ }^{11}$.

Sin duda alguna, esta decidida posición antisemita de persecución a los judíos estuvo relacionada con distintos aspectos como la alianza con la

9 Mario Avagliano sostiene que en los primeros años del fascismo italiano el "problema judío" no existía, basándose en unas palabras del propio Mussolini en Il popolo d'Italia, en 1920: «Italia no hace absolutamente ninguna diferencia entre judíos y no judíos [...]; los judíos italianos tienen aquí la nueva Sión, en nuestra adorable tierra». AVAGLIANO, Mario, «Ebrei e fascismo, storia de la persecuzione», en Patria Indipendente, 6-7, 2002, en URL: http://www.storiaxxisecolo.it/fascismo/fascismo18.htm [consultado el 6 de julio 2014].

10 Uno de los aspectos más relevantes de esta campaña antijudía se desarrollará en la prensa. Véase URL: http://www.museoshoah.it/link.asp?id=campagna-stampa [visitado el 8 de noviembre 2014]

${ }_{11}$ BARTOSOVÁ, Jana, Gli ebrei nell'Italia fascista. Lo sviluppo e gli obiettivi della politica razziale in Italia, (Tesis doctoral), Masarykova Univerzita, Brno (República Checa), 2006, p. 17. URL: http://is.muni.cz/th/74230/ff_b/BAK_1_.PRACE.pdf [visitado el 22 de mayo 2013]. 
Alemania nazi, el desarrollo de una política racista, sobre todo contra los africanos en Etiopía, la construcción de una «dignidad imperial» y la estructuración del totalitarismo ${ }^{12}$. La finalidad de esta nueva política era eliminar a los judíos y judías de la sociedad y de la nación italiana: había que inculcar en la conciencia colectiva la imagen de un judío extraño e inadmisible, tanto desde el punto de visto étnico como espiritual ${ }^{13}$. En cuanto a la visión de este judío como extraño e inadmisible espiritualmente, no podemos dejar de hacer mención a la teoría del "racismo espiritual” de Julius Evola:

El nudo de la doctrina establecida por Evola sobre la raza, se centra en las diferencias entre cuerpo, alma y espíritu. Para Evola, la raza no es solamente un bagaje biológico o psicológico, sino algo mucho más profundo. De la misma forma que existe una "raza del cuerpo", Evola nos habla de una "raza del espíritu14.

En un primer momento las persecuciones se llevaron a cabo de manera parcial, en torno a características cuantitativas y cualitativas. En cuanto a las personas que debían ser objeto de las persecuciones, quedarían definidas en el documento teórico oficial Il fascismo e i problemi della razza, publicado el 14 de julio de 1938, en el que el concepto de raza aparece ligado únicamente a aspectos puramente biológicos. Y respecto a los judíos extranjeros, aquéllos que no tenían nacionalidad italiana, se tomaron las siguientes medidas: prohibición de ingreso de nuevos judíos en el país, alejamiento de aquéllos que no llevaran residiendo en la península al menos veinte años y prohibición, incluso, de tránsito por el país. Éstas fueron las medidas tomadas sobre el papel, pero

\footnotetext{
12 En la historiografía española, los caracteres del Estado mussoliniano en perspectiva comparada con el Estado nazi, en FERNÁNDEZ GARCÍA, Antonio, RODRÍGUEZ JIMÉNEZ, José Luis, Fascismo, Neofascismo y Extrema Derecha, Madrid, Arco/Libros, 2001, pp. 30-33; autores que señalan las diferencias en cuanto al tema del racismo entre la Alemania nazi y la Italia fascista, y que el Manifiesto de defensa de la raza de 1938 en Italia, pese a sostener la desigualdad de las razas humanas y la aproximación de forma lenta de la Italia fascista a los ideales de su aliado natural, las medidas de 1938 deben entenderse como recursos de refuerzo de los lazos con su aliado antes que aplicación de principios intrínsecos del régimen.

13MINERBI, A., Il veleno delle parole. La propaganda antisemita del fascismo en 1938, Milán, CDEC, 2002, en URL: http://www.cdec.it/home2_2.asp?idtesto $=185 \&$ idtesto1 $=887 \&$ son $=1 \&$ figlio $=878 \& l e v e l=2$ [visitado el 7 de julio 2014]. 14 En URL: http://juliusevola.blogia.com/2006/102101-sintesis-de-la-doctrina-de-la-raza-o8raza-y-espiritu.php [visitado el 6 de noviembre 2014].
} 
sabemos que la realidad fue otra, y que no se pudieron llevar a la práctica en su totalidad.

Es ahora cuando el gobierno toma la decisión de comenzar con el internamiento en comunas o campos, aunque esta medida no fue acompañada de la violencia física y simbólica de otros regímenes, ni fueron obligados a portar una identificación distintiva amarilla o de otro tipo. Finalmente, en junio de 1943, se instituyeron cuatro campos de internamiento y trabajos forzados. Todos los perseguidos fueron censados y la pertenencia judía mencionada en todos los certificados, a excepción del pasaporte y el carnet de identidad para facilitar el éxodo. Para apreciar la situación que estos judíos llegaron a vivir, recogemos las palabras de un profesor universitario: «me ha sido truncada improvisadamente toda actividad como ciudadano y como profesor: he sido expulsado de la cátedra y, a través de mis libros, asisto a la destrucción de cuanto formaba la razón misma de mi vida» ${ }^{5}$.

Entre otras medidas contra los ciudadanos judíos se tomaron las siguientes: no podían poseer bienes inmuebles que superaran el valor de 5.0oo liras, se les prohibió la posesión de aparatos de radio, se les retiró la licencia para conducir, el cese de las publicaciones de los periódicos judíos, la prohibición de celebrar sus festividades, y las sinagogas comenzaron a ser atacadas y destruidas, comenzando por las de Ferrara, Turín, Casale Monferrato y Trieste ${ }^{16}$.

\section{La persecución de la vida}

La primera caída de Mussolini, el 25 de julio de 1943, conllevó la firma de un armisticio con los gobiernos de Estados Unidos y Gran Bretaña, y a partir de éste la península quedaba dividida en dos partes: al sur de la línea del frente (Italia meridional y las islas) bajo poder anglo-americano y el Reino de Italia; el norte bajo el poder aliado-ocupante alemán y la nueva República Social Italiana (RSI), con sede en Salò.

${ }^{15}$ SARFATTI, Michele, La Shoah in Italia, Torino, Einaudi, 2005, p. 87.

${ }^{16}$ Ibidem, p. 92. 
Las primeras acciones que tuvieron como finalidad el arresto de judíos se llevaron a cabo el sábado 9 de octubre en Trieste y el sábado 16 en Roma ${ }^{17}$. Tras estos primeros arrestos vinieron otros como los de la región de la Toscana, Bolonia y Turín-Génova-Milán y entre septiembre de 1943 y enero de 1944, los alemanes deportaron a la mayor parte de los judíos que habían sido arrestados, con la colaboración italiana, suficientemente documentada ${ }^{18}$.

El 30 de noviembre de 1943 se decretó el arresto de todos los judíos, pertenecieran a la nacionalidad que pertenecieran, y su posterior reclusión en campos provinciales, a la espera de reunirlos en campos de concentración especiales. En ese momento se trasladó a las víctimas al único campo nacional preparado hasta ese momento, el campo de Fossoli di Carpi (Módena). Posteriormente serían recluidos en el Campo di transito o Campo de BozenGries (en alemán, Durchgangslager Bozen) en Bolzano ${ }^{19}$, más al norte y, por tanto, más práctico para los alemanes. También cabe señalar la existencia de la Risiera di San Sabba, en Trieste, primero como campo de concentración y, durante la ocupación nazi, también de exterminio (1944-45) ${ }^{20}$. Fueron eximidos aquéllos que estuvieran gravemente enfermos, los mayores de setenta años y los que tuvieran un progenitor o cónyuge de raza aria.

Serían los alemanes los que se encargaran de las deportaciones, principalmente al campo de Auschwitz-Birkenau y, en menor medida, a Bergen Belsen y Ravensbrück. La mayoría fueron destinados a cámaras de gas, o murieron frecuentemente por agotamiento como consecuencia de los trabajos forzosos, por asesinatos, por las condiciones de vida o por las evacuaciones

\footnotetext{
${ }_{17}$ Cabe pensar que la elección del sábado como día de arresto fue una medida práctica, puesto que la mayoría de los judíos se encontraría en sus domicilios guardando el precepto del shabbat. ${ }^{18}$ SARFATTI, Michele, La Shoah in Italia, cit., p. 100. El film de Constantin Costa-Gavras: "Amén" (Francia-Alemania), 2002, 132', aborda, desde una perspectiva crítica, la diplomacia del Vaticano con respecto al Holocausto, así como la gesta heroica de muchos sacerdotes que se opusieron a la barbarie incluso con su vida, caso del jesuita protagonista de la película, el joven padre Ricardo, frente a la indiferencia y complicidad de otros. Véase URL: http://www.filmaffinity.com/es/film651336.html [visitado el 30 de julio 2014].

19 GIACOMOZZI, Carla, PALEARI, Giuseppe, Il lager di Bolzano. Note storiche e documenti, Progetto "Storia e memoria: il Lager di Bolzano", Comune di Bolzano, 2006, URL: http://www.comune.bolzano.it/UploadDocs/6714_Lager_BZ_it.pdf [visitado el 3 de noviembre 2014].

${ }^{20}$ Véase el siguiente enlace, URL: http://www.risierasansabba.it/la-storia/ [visitado el 3 de noviembre 2014].
} 
conocidas como «marchas de la muerte». La confiscación de sus bienes ${ }^{21}$ se llevó a cabo mediante un decreto de 4 de enero de $1944^{22}$, que establecía que éstos pasarían a ser propiedad del Estado, administrándolos a través del Ente di gestione e liquidazione immobiliare (Egli)23. En junio-agosto de 1944 fueron liberadas Roma y Florencia; en enero de 1945, Auschwitz; en abril de 1945, la llanura padana. Así se puso fin a la sangre y al Holocausto nazi-fascista.

\section{El caso español: Franco y los judíos}

\subsection{Antecedentes: II República y Guerra Civil}

«El advenimiento de la Segunda República en abril de 1931, lejos de cuestionar la política prosefardí de Alfonso XIII, ofrecerá, en cambio, un contexto mucho más favorable al acercamiento hispanojudío»24. Pero no fue así de sencillo, pues durante el gobierno republicano, la actuación no fue igualitaria y lineal en el tiempo, si bien el nuevo régimen político republicano inició una campaña llevada a cabo por líderes como Alcalá Zamora, Fernando de los Ríos, Lerroux, o diplomáticos en el exterior como Américo Castro o Madariaga, en la que se invitaba oficialmente a los judíos a volver a la antigua Sefarad, considerado como la reparación del «error histórico de la expulsión»25. Américo Castro, haciendo referencia a la expulsión, la calificará de pérdida incalculable para España. Este hecho se puede poner en conexión con la nueva ley para la concesión de la nacionalidad española por carta de naturaleza a los sefardíes

\footnotetext{
${ }^{21}$ En el siguiente enlace se muestran documentos de la época referentes a la confiscación de bienes. URL: < http://www.museoshoah.it/link.asp?id=confische $>$ [visitado el 8 de noviembre 2014]

${ }^{22}$ En el siguiente enlace puede verse el decreto de confiscación firmado por el Duce. URL:

< http://www.museoshoah.it/link.asp?id=sequestro-beni > [visitado el 10 de noviembre 2014]

${ }^{23}$ En cuanto a la Resistencia y la lucha clandestina, y la participación judía, no podemos adentrarnos por las limitaciones extensivas de este artículo, pero puede consultarse SARFATTI, Michele, La Shoah in Italia, op. cit. El origen y desarrollo de la Resistencia en Italia durante los años de la clandestinidad, en AMENDOLA, Giorgio, La lucha antifascista, Barcelona, Ed. Laia, 1980; autor que fue un destacado en la historia antifascista italiana, miembro del comando de las Brigadas Garibaldi, responsable del Triunvirato Insurreccional piamontés, y miembro del PCI desde 1945.

24 ROZENBERG, Danielle, La España contemporánea y la cuestión judía, Madrid, Ed. Marcial Pons, 2010, p. 136.

25 GONZÁLEZ, Isidro, «Los judíos y la Segunda República», in Historia, 16, 299, 2001, p. 83.
} 
originarios de España, de la que se deriva que la expulsión y sus consecuencias eran consideradas como un proceso histórico inconcluso. Una de las primeras figuras históricas que cabe mencionar en este sentido, aunque más adelante hablaremos de él, fue Ángel Pulido Fernández²6.

No obstante, este proceso iniciado con el gobierno de la Segunda República, se vio influenciado por la oleada antisemita que, en directa relación con los acontecimientos, se estaba produciendo en Europa Central, especialmente en Alemania y Austria, así como por el ataque de algunos partidos de la derecha española, que asociaban el judaísmo con el comunismo y la masonería. Fue a partir de 1932 cuando la cuestión judía se politizó y comenzó a alcanzar un mayor protagonismo, aunque con diferencias, dependiendo de cada partido o corriente ideológica, y desde ese momento se planteó la disyuntiva de ofrecer la nacionalidad a los sefarditas, de manera especial a aquéllos que huían del horror nazi en Alemania y del comunismo en la Unión Soviética.

Como decíamos, esta política de retorno no seguirá una tendencia lineal, pues irá sufriendo variaciones conforme se vayan sucediendo en el poder los distintos gobiernos republicanos. Así, al comienzo de la Segunda República será cuando dé comienzo esta política, pero se verá frenada entre 1934-1936 con la llegada al gobierno del centro-derecha, y vivirá su impulso definitivo con la presidencia de Manuel Azaña en febrero de 1936, cuando esta medida se impulse de manera más clara, con una protección especial a los judíos sefarditas griegos.

Pero el comienzo de la Guerra Civil, el 18 de julio de 1936, supuso para la relación de los judíos con el gobierno republicano el cese de toda la actividad relacionada con las nacionalizaciones, siendo ahora la República quien busque el apoyo de los judíos a su causa.

La situación de los judíos europeos alcanzó su punto más delicado en 1938, cuando el antisemitismo comenzó a tener un desarrollo importante durante el Tercer Reich, desembocando en la tristemente conocida como Noche de los Cristales Rotos (9 de noviembre de 1938), en la que se destruyeron numerosos

\footnotetext{
26 Véase BEL BRAVO, María Antonia, «Ángel Pulido y el sefardismo internacional», en Hispania Sacra, 108, 2008, pp. 327-349 y también el ensayo de TOUBOUL TARDIEU, Eva, «Ángel Pulido Fernández, un régenérationniste sui generis», in Bulletin d'histoire contemporaine de l'Espagne, 47, 2012, pp. 217-230.
} 
negocios regentados por judíos y sinagogas. Ante estos hechos, el gobierno republicano recibió por parte de Bernard Lecache, y a través de Marcelino Pascua, embajador en París, un informe detallado de las actuaciones que se iban a llevar a cabo en la 'Asamblea Mundial contra el Racismo y el Antisemitismo', en defensa de los pueblos amenazados por estas ideologías, ya fuera de carácter nacional o internacional.

Paralelo al despliegue del antisemitismo nazi, fue notorio el apoyo recibido por la República de parte del mundo judío, especialmente desde el ámbito intelectual, que se vio materializado en dos vías fundamentales: la prensa judía y la presencia de judíos en la Brigadas Internacionales ${ }^{27}$. Fueron muchos los periódicos judíos que decidieron apoyar a la República, de hecho, según Arno Lustiger, será en el diario Naylaben de Nueva York, un periódico judío publicado en yidish, donde aparezca por vez primera el apelativo de fascistas. $\mathrm{Y}$ también fue un periódico estadounidense de izquierdas, el Jewish Life, el que advirtió de las terribles consecuencias de que los rebeldes se hicieran con la victoria final:

Una victoria de Franco en España sería la señal para una conflagración mundial. Significaría la maldición para esos millones de seres humanos que pertenecen a las minorías nacionales de diversos países europeos; significaría muerte y perdición para millones de judíos. iFranco no debe ganar!28.

En cuanto a las reacciones frente al conflicto bélico español en Italia, Mussolini llevó a cabo una campaña basada, fundamentalmente, en dos acusaciones: que los judíos fundamentaban ideológicamente al Frente Popular y al comunismo soviético en España, y que prestaban un relevante apoyo económico a la causa republicana.

27 IBÁNEZ SPERBER, Raquel, «Judíos en las Brigadas Internacionales. Algunas cuestiones generales», in Historia Actual Online, 9, 2006, p. 108. URL:

$<$ http://dialnet.unirioja.es/servlet/articulo?codigo=2188053 > [visitado el 7-08-14].

${ }^{28}$ LUSTIGER, Arno, iShalom libertad! Judíos en la Guerra Civil Española, Barcelona, Flor del Viento Eds., 2001, p.63. Resulta paradójico y curioso que el conocimiento que tenemos sobre la participación activa de apoyo de los judíos al bando republicano, venga dado precisamente por fuentes de la Alemania nazi y la Italia fascista, que utilizaron la presencia judía en el bando republicano como argumento esgrimido para justificar su intervención. Desde la historiografía italiana cabe destacar el estudio de Luciano Tas (TAS, Luciano, La partecipazione ebraica nella Guerra Civile Spagnola, in Italiani nella guerra di Spagna. Un contributo di libertà, Roma, Istituto di Studi per la storia del Movimento Repubblicano, 1982). 
No cabe duda que la Guerra Civil despertó todo tipo de sentimientos y apoyos en el contexto internacional, como también es cierto que la inmensa mayoría del judaísmo del continente europeo se posicionó a favor de la causa republicana.

\subsection{Los judíos españoles tras la victoria de Franco (1939-45)}

El periodo cronológico elegido, 1939-1945, responde a que será tras la Guerra Civil, y hasta 1945, cuando el régimen de Franco conoció su fase totalitaria de corte más fascista, y en el que, por tanto, las ideas y medias antisemitas se dejaron ver de manera más evidente. En palabras de Maite Ojeda: «El triunfo del franquismo no sólo significó la recuperación del vínculo privilegiado entre Iglesia y Estado, sino la exclusión, de derecho y de hecho, de los no-católicos del acceso a la igualdad jurídica, incluyendo la adquisición de la ciudadanía española»29.

No obstante, el antisemitismo en los primeros años de la España franquista, según la tesis de José Lisbona, fue difundido de manera exagerada en el exterior, incluyendo informaciones falsas sobre leyes antijudías. De hecho, la Embajada alemana en Madrid presentará quejas por la escasa presencia de antisemitismo en España, tal y como ellos lo entendían. Aun así, no podemos cometer el error de considerar a la España de la época un país con ausencia de antijudaísmo, pues los judíos encontraron trabas y problemas, tales como la prohibición de la circuncisión, los enlaces matrimoniales y los entierros judíos. A estas medidas habría que sumar la prohibición de registrar a los hijos de judíos si no habían sido bautizados, y la obligación de los niños y niñas en edad escolar de asistir a clases de religión católica.

Habrá que esperar a 1945, cuando la Ley de Educación Primaria permita a los hijos de extranjeros no católicos no asistir a clases de religión, y el Fuero de los Españoles (17 de julio) otorgue la posibilidad de la práctica privada de religiones no católicas, abriéndose las sinagogas que habían sido cerradas, junto

29 OJEDA MATA, Maite, «Sefardíes, identidad y ciudadanía en la España contemporánea (siglo XIX $y$ primera mitad del XX)», en http://www.upf.edu/grimse/ pdf/Maite Ojeda. Sefardxes y ciudadanxa xresumenx.pdf [visitado el 3-11-2014]. 
con los cementerios. Aun así, el férreo control ideológico que se llevó a cabo sobre el sistema educativo, llevará a incluir en los manuales una «historia oficial» que presentaba a los judíos como enemigos históricos del país, llegando incluso a culpabilizarlos de la guerra.

Pero fue en 1941 cuando se llevó a cabo la medida más amenazante y peligrosa contra los judíos españoles, y no por casualidad, sino coincidiendo con el momento de mayor relación entre la España franquista y la Alemania de Hitler. La Dirección General de Seguridad ordenó a los gobernadores civiles provinciales redactar y enviar informes sobre todos los judíos que residían en el país, destacando entre los datos a recoger, la inclinación política y el «grado de peligrosidad» $3^{0}$.

En cuanto al discurso público de Franco, podemos encontrar declaraciones de carácter abiertamente antisemita: alianza del espíritu judío con el marxismo, equiparación de los términos capital-judaísmo-marxismo, y una carta dirigida al Papa Pío XII en la que acusaba al judaísmo de llevar a cabo un programa de odio contra la civilización católica. A diferencia del caso italiano, en el caso franquista no aparecen las teorías de la raza, con una única referencia en un discurso al hablar de las razas que se caracterizaban por su codicia. Podemos asegurar que Franco se posicionó contra los judíos, pero su actuación distaba mucho del antisemitismo radical de la Alemania nazi o la Italia fascista. Resulta muy interesante para ver la imagen que se proyectaba del judío en la España franquista la obra de Álvarez Chillida3.

\subsection{El régimen franquista frente al Holocausto}

Los consulados de España, Turquía, Chile, Suiza e Irán pusieron interés en que sus ciudadanos detenidos en París fuesen liberados, pero a principios de septiembre de 1941, sólo Italia lo había conseguido. Así las cosas, a mediados de 1942 y en contra de lo recomendado por el embajador alemán en París, Otto

3o ISRAEL GARZÓN, Jacobo, «El Archivo Judaico del Franquismo», en Raíces, 33, 1977, p. 60. URL:

< http://observatorioantisemitismo.fcje.org/wp-content/uploads/wpcf7_uploads//2009/11/ElArchivo-Judaico-del-Franquismo.pdf $>$ [visitado el o3 de julio 2014].

${ }^{31}$ ÁLVAREZ CHILLIDA, Gonzalo, El antisemitismo en España. La imagen del judío (18122002), Madrid, Marcial Pons, 2002. 
Abetz, el Ministerio de Asuntos Exteriores alemán decidió eximir de las deportaciones de Francia a Auschwitz, a los judíos de los países aliados, neutrales e, incluso en algún caso, enemigos. A pesar de la insistencia de Adolf Eichmann en las deportaciones (su objetivo era que todo el pueblo judío hubiese sido deportado, como muy tarde, a mediados del año 1943), la Alemania nazi dio, como ultimátum, dos alternativas: la repatriación o la deportación.

El conocimiento que el gobierno franquista tenía sobre la situación del Holocausto, remite a la pregunta acerca de hasta qué punto los dirigentes españoles eran conocedores o no de la persecución y asesinato de los judíos. En palabras de Martín de Pozuelo,

«el exterminio de los judíos y otras minorías por parte de los nazis no fue un secreto que se descubrió por sorpresa a final de la II Guerra Mundial tal como nos han intentado hacer creer. Se supo lo que sucedía -y se supo con detalle- pese a que los nazis trataron de ocultarlo [...]»32.

Dicho autor señala el noble, pero aislado, papel jugado por ciertos diplomáticos españoles en la protección de los judíos, derivó en una visión falaz explotada por el propio régimen de un Franco filosemita. Esta supuesta acción humanitaria de Franco, se ha visto desmentida y desacreditada por diversos trabajos históricos desde mitad de los años setenta, tal y como afirma Rozenberg 33 .

Las primeras informaciones de lo que estaba ocurriendo llegaron de manos de un grupo de médicos que había estado en Austria y Polonia, que avisaron en un informe al ministro español de Gobernación sobre la eutanasia y el encierro de la población judía en guetos. Posteriormente se desarrollará uno de los

\footnotetext{
$3^{2}$ MARTÍN DE POZUELO, Eduardo, El franquismo, cómplice el Holocausto, Barcelona, La Vanguardia Ediciones, 2012, p.17.

33 ROZENBERG, Danielle, La España contemporánea y la cuestión judía, op. cit., p.214. Entre otras aportaciones cabe destacar: la del historiador israelí AVNI, Haïm, España, Franco y los judíos, Madrid, Altalena, 1982; las de Antonio Marquina (MARQUINA, Antonio, La España de Franco y los judíos, in MACÍAS KAPÓN, U. et al., Los judíos en la España contemporánea. Historia y visiones, 1898-1998, Cuenca, Universidad de Castilla-La Mancha, 2000); o tesis como las de OUAHNON, Josette, L'Espagne et les juifs séfardites depuis 1920, (Tesis doctoral), Universidad de la Sorbona, 1981, BLIN, Pascale, Franco et les juifs: paroles et actifs. De sa rencontre avec les juifs à la reconnaissance de la communauté juive d'Espagne (1968): un itinéraire controversé, Paris, Etudes ibériques, 1992, así como la de ROTHER, Bernd, Franco y el Holocausto, Madrid, Marcial Pons, 2005.
} 
hechos más conocidos de esta época con respecto a la persecución y eliminación de los judíos: el papel jugado por algunos diplomáticos españoles, cuyas acciones de rescate fue encomiable, no dudando en algunos casos ir más allá de sus competencias, infringiendo medidas ministeriales e incluso arriesgando su propia vida. Entre estos diplomáticos habría que destacar los siguientes nombres: Bernardo Rolland (París), Sebastían Romero Radigales (Atenas), que ha recibido en el año 2014 la distinción de Justo entre las Naciones, Ginés Vidal (Berlín), Julio Palencia (Sofía) llamado “el magnífico amigo de los judíos”, José Rojas y Moreno (Bucarest) y Ángel Sanz Briz (Budapest) al que el Memorial Yad Vashem otorgó la distinción de "Justo entre las Naciones" 34 . No obstante, y pese a la actuación de estos diplomáticos, es necesario seguir reflexionando sobre la complicada relación entre España y los judíos, ya que por lo visto:

[...] no es solamente la conexión Franco-Hitler en el contexto europeo lo que nos vincula al Holocausto, sino el hecho de que en la España de Franco y mucho más allá de la dictadura, el genocidio nazi fuera considerado un tema "de judíos y alemanes". ¿Cómo pensar que eso no nos afecta - recoge el autor palabras de Reyes Mate - cuando tantos españoles fueron educados en una España franquista, es decir, con categorías que privaban de significación a esta catástrofe?35.

\subsection{La defensa de los judíos por Franco: ¿̇mito o realidad?}

Fue ya durante la II Guerra mundial cuando el gobierno franquista comenzó a querer presentarse como salvador de los judíos ante las potencias aliadas occidentales y ante las organizaciones judías. A esto contribuyó de manera especial el embajador de España en Washington, quien permitió que en Estados Unidos se proyectara una imagen positiva de España en este sentido.

En un primer momento, el rabino Maurice Perlzwieg, presidente del Congreso Mundial Judío (CMJ), envió varias peticiones al gobierno de Franco

\footnotetext{
34 El papel jugado por estos diplomáticos ha sido recogido en una exposición itinerante promovida por el Centro Sefarad-Israel con sede en Madrid y el Ministerio de Asuntos Exteriores de España, bajo el título "Visados para la libertad", 2014.

35 BAER, Alejandro, «Los vacíos de Sefarad. La memoria del Holocausto en España», en Política y Sociedad, 48, 3/2011), p. 504. URL:

< http://revistas.ucm.es/index.php/POSO/article/view/36416/36918 > [visitado el 8 de julio 2014].
} 
para que éste le permitiera ayudar a los refugiados en España, a la vez que solicitaba que el gobierno franquista interviniese ante Alemania a favor de la evacuación de niños judíos. Las peticiones del CMJ fueron reiteradas, pero su gran decepción vino cuando se supo que, en la primavera de 1944, España había establecido que el requisito sine qua non para la entrada de más sefardíes en la Península, era su posterior evacuación a otros países.

No será hasta el final de la guerra, cuando se desarrolle de manera específica una cooperación entre organizaciones judías y el gobierno franquista, en el que ambas partes salían beneficiadas. Las organizaciones intentaron salvar a un gran número de judíos de los campos de concentración y exterminio y, como contrapartida, el gobierno de Franco sería debidamente reconocido por los medios de comunicación de los aliados. Por supuesto, para Franco no se trataba, en absoluto, de lograr buenas relaciones con los judíos y ayudarlos en su situación, como de asegurarse una posición pública favorable en la política internacional de posguerra. Haim Avni lo describe así:

\begin{abstract}
El interés de España en mejorar las relaciones públicas no fue lo suficientemente fuerte como para actuar como impulso para la salvación. Además, este interés ha estado ampliamente servido por las estrechas relaciones que embajadores españoles labraron con un número de líderes judíos, los cuales beneficiaron a España fomentando el mito de la amplitud de sus actividades a la hora de salvar judíos ${ }^{36}$.
\end{abstract}

Si Franco puede ser considerado como salvador de los judíos, ya hemos visto que es muy relativo. De hecho, Martín de Pozuelo afirma que el diplomático franquista Sanz Briz envió a Madrid, basándose en lo que se conocen como los Protocolos de Auschwitz37, información de lo que estaba sucediendo en los campos de concentración, que incluía el dato de que se estaba utilizando grasa humana para elaborar jabón. Este documento se archivó en Madrid sin darle

\footnotetext{
${ }^{36}$ ROTHER, Bernd, Franco y el Holocausto, cit., p. 396.

37 Denominación que hace referencia a dos informes sobre los asesinatos masivos que se llevaron a cabo en Auschwitz, basados en datos proporcionados por cuatro prisioneros que lograron escapar en 1944. Los protocolos fueron enviados a través de diversos canales a Occidente. La información llegó al Departamento de Estado norteamericano el 16 de junio, y la $B B C$ difundió partes del informe el 18 de junio de 1944. Véase ZADOFF, Efraim, Enciclopedia del Holocausto, Jerusalén, E.E.Z. Ediciones Jerusalén, 2004, pp. 138-139.
} 
importancia alguna, por lo que Franco, siguiendo a Martín de Pozuelo, permitió la muerte de judíos de nacionalidad española pese a poder salvarlos mediante las oportunidades reiteradas que le ofreció la Alemania nazi de deportarlos a España. Es más, las veces que el gobierno franquista ayudó y socorrió a los judíos, fue por causas ajenas a su voluntad y por intereses propagandísticos, concluye Pozuelo. También el historiador de la Universidad de Jerusalén, Yehûda Bauer, especializado en la Shoah, reflexionó sobre esta cuestión en su obra American Jewry and the Holocaust, en la que expuso la hostil indiferencia del gobierno español, haciendo referencia a los miles de judíos que el franquismo dejó de salvar.

\section{Conclusiones}

Comenzaremos apuntando que en este artículo, en el que se compara la actitud de dos regímenes dictatoriales frente a un mismo colectivo, el pueblo judío, a priori ambos podrían resultarnos similares, pero a lo largo de este estudio hemos podido comprobar cómo las políticas del fascismo italiano y español para con las comunidades judías, pueden presentar puntos convergentes, pero para nada idénticas. Esta hipótesis que apuntábamos al comienzo del artículo, la similitud de dos dictaduras fascistas en su comportamiento hacia "lo judío", se va diluyendo conforme avanzamos en la investigación.

Si nos planteamos, en primer lugar, cuál era la situación de los judíos en ambos países antes de la llegada al poder de Mussolini y Franco respectivamente, comprobaremos rápidamente que la situación de la comunidad italiana nada tenía que ver con la de la española. Nos encontramos, como hemos señalado, con una comunidad judía italiana totalmente integrada en la sociedad (lo que podríamos dar en llamar judíos “italianizados”), llegando incluso a desempeñar su labor en importantes puestos políticos - recordemos la presidencia del Consejo de Ministros de Luzzati -, a lo que habría que sumar la presencia en movimientos políticos de distinto posicionamiento ideológico.

Por el contrario, en España observamos una comunidad judía que comenzará a alcanzar visibilidad con la llegada de la Segunda República (a pesar 
de intentos anteriores, como el de Ángel Pulido, "El apóstol de los judíos”) y sus intentos de regreso de los judíos a Sefarad, pero cuya propuesta de concesión de nacionalidad siempre fue puesta en entredicho y se hizo uso de ella como pretexto para numerosos enfrentamientos políticos. Vemos, por tanto, que mientras en Italia, los autores nos hablan de que en los judíos de la península itálica prevalecía la nacionalidad a la pertenencia al grupo/comunidad, o por lo menos ambas cosas no eran excluyentes, en España estamos haciendo referencia a unos judíos a los que se les quiere facilitar, de manera oficial, el retorno, tras la expulsión de 1492.

Atendiendo ahora a la situación con ambos dictadores ya en el poder, las actuaciones llevadas a cabo también fueron distintas. Sería conveniente recordar las palabras de Mussolini en uno de sus discursos tras su llegada al poder, en las que presentaba a Italia como la nueva Sión, antes, por supuesto, de que el Pnf se declarase abierta y oficialmente antisemita. Mussolini, en sus primeros años de gobierno, se debate entre el apoyo y la condena a los judíos, años en los que prima la ambigüedad. Este carácter ambiguo será la principal característica de la postura franquista durante los primeros años de gobierno: la controversia y la ambigüedad sí serán un punto común entre ambas dictaduras.

Pero, pasados los primeros años de gobierno, en Italia se comenzó a desarrollar una persecución oficial y pública de los judíos que, iniciada con la destrucción de sus derechos, finalizó destruyendo sus vidas. Este giro radical está directamente relacionado con la presión realizada por el Tercer Reich sobre Mussolini, hecho que Franco pudo "evitar" con el inminente final de la Guerra Civil. Recordemos las palabras que recogíamos de aquel profesor de universidad y cómo vio truncada su vida de la noche a la mañana, para hacernos una idea del giro que experimentó la postura mussoliniana.

Por esa presión y relación de Italia con Hitler, las políticas llevadas a cabo (leyes raciales) y las actuaciones (persecuciones, detenciones, deportaciones) en Italia se asemejaron más al llamado "perfecto plan” alemán de acabar con la existencia del pueblo judío. Es por ello que, actuaciones como los ataques a sinagogas, la confiscación de bienes y la existencia de campos de internamiento y trabajos forzosos, no puede sino recordarnos a las medidas del gobierno nazi. En la España franquista, sin que el latente recelo hacia los judíos pase 
inadvertido (recordemos la existencia del Archivo Judaico), las medidas que se llevaron a cabo nunca alcanzaron en agresividad a las italianas, aunque esto no puedo hacernos olvidar la reclusión en cárceles en penosas condiciones de vida.

Si buscamos hacer un balance de la actitud del gobierno de Franco, podemos exponer las palabras de Rother:

\begin{abstract}
No se le puede atribuir a la dictadura de Franco que haya apoyado la persecución judía llevada a cabo por el nacionalsocialismo. Este gobierno estaba tan ligado a los valores católicos tradicionales que no pudo compartir las terribles consecuencias que los nacionalsocialistas extrajeron de su ideología racista desde el principio de la Segunda Guerra Mundial. Sin embargo, la dictadura tampoco fue un refugio para los judíos perseguidos ${ }^{3}$.
\end{abstract}

Cabe recordar que la dictadura franquista sí facilitó el tránsito de los judíos hacia otros países, pero nunca permitió la permanencia de éstos en la península, más por temor político (contubernio judeo-masónico) que por otras cuestiones. Avni recoge, con palabras certeras, cuál era la actitud franquista para con el paso de los judíos: debían pasar «como la luz por el cristal, sin dejar rastro»39. Pero no debemos caer en la tentación de considerar, tanto en un caso como en otro, en la Italia de Mussolini y la España de Franco, que no actuar de manera directa (en Italia sólo durante los primeros años) exime de responsabilidad. Dicho de otra manera: se puede "pecar” de acción pero también de omisión.

$3^{8}$ ROTHER, Bernd, Franco y el Holocausto, cit., p. 405.

39 AVNI, Haïm, España, Franco y los judíos, cit., p. 209. 


\section{* El autor}

David Pérez Guillén es licenciado en Historia por la Universidad de Murcia (España). Ha cursado el Máster en Historia Social Comparada y recientemente ha emprendido sus estudios doctorales en la Universidad de Murcia, donde pretende analizar la posición de los regímenes fascistas (la Italia de Mussolini, la España de Franco y el Portugal de Salazar) ante las comunidades judías y el Holocausto. Recientemente ha publicado: Política, economía, sociedad y cultura en la India (siglos XV-XIX), in CREMADES GRIÑÁN, Carmen María (coord.), Política, economía, sociedad y cultura afroasiática en la Edad Moderna, Murcia, Ed. Diego Marín, 2011; «De la amistad al odio: las comunidades judías bajo la dictadura mussoliniana», in La Razón Histórica. Revista Hispanoamericana de Historia de las Ideas, 24, 2013, pp. 32-58.

URL: < http://www.studistorici.com/progett/autori/\#Pérez-Guillén >

\section{Per citare questo articolo:}

PÉREZ GUILLÉN, David, «Mussolini, Franco y los judíos: una relación controvertida», Diacronie. Studi di Storia Contemporanea : Il diritto miltante, 29/12/2014,

URL:< http://www.studistorici.com/2014/12/29/perez-guillen_numero_20/ >

\section{Diacronie Studi di Storia Contemporanea $\beta$ www.diacronie.it}

Risorsa digitale indipendente a carattere storiografico. Uscita trimestrale. redazione.diacronie@hotmail.it

Comitato di redazione: Jacopo Bassi - Luca Bufarale - Elisa Grandi - Deborah Paci - Fausto Pietrancosta - Matteo Tomasoni - Luca Zuccolo 